\title{
COVID-19 en un país sin justicia social
}

\author{
COVID-19 in a country without social justice
}

Ricardo Páez Moreno*

Estimado editor:

Me permito poner a su consideración las siguientes reflexiones en relación al COVID y la ausencia de justicia social en nuestro país.

Según el estudio de Alejandro Celis y Darío Nava titulado Patología de la pobreza publicado desde 1970 en la Revista del Hospital General de México,' las enfermedades de la pobreza continúan y son las que generan una alta mortalidad en este sector de la población, tales como diarreas, desnutrición, neumonías o diabetes. Este dato contrasta con quienes tienen posibilidades de una mejor calidad de vida y de atenderse por otros medios, como es el caso de pacientes que recurren a la medicina privada o que se pueden pagar un seguro de vida.

Los desniveles de atención médica en México son graves entre la medicina pública y privada, y se dan aun entre quienes tienen acceso a los servicios de salud por su condición de contar con un empleo formal, es decir, los asegurados por la medicina pública frente a quienes están en el desamparo y son atendidos por los servicios para la población abierta. Una de las causas importantes, entre otras, estriba en que el Gobierno invierte muy poco en salud: $2.8 \%$ del PIB en gasto público, como consecuencia se genera que la proporción de gasto de bolsillo sea de $45 \%$ y que el sistema opere con un enorme déficit de personal.2

El nivel socioeconómico influye considerablemente en la salud de una población. Los sectores más desprotegidos y pobres son los que han aportado más de $84 \%$ de los decesos por COVID. ${ }^{3}$ Incluso en los Estados Unidos, 76\% de los pacientes con necesidad de intubación no llegaron al hospital, y 50\% han muerto sin diagnóstico en vida por probable COVID por falta de pruebas. ${ }^{4}$ Según Héctor Hernández Bringas, investigador titular del Centro Regional de Investigaciones Multidisciplinarias de la UNAM, a partir de información de certificados de defunción en México: 70\% tienen escolaridad de primaria o inferior; y 30\% de las defunciones lo explican los no remunerados, los jubilados, los pensionados, las amas de casa y los estudiantes. En los hospitales del Sector Salud han ocurrido $40 \%$ del total de las defunciones. Esto tiene que ver con un mal estado de salud preexistente y a su vez con el escaso acceso a servicios de salud de calidad, pero además refleja a los sectores que han tenido que seguir saliendo a trabajar en la contingencia por necesidad económica. ${ }^{5}$

Ante ello, el discurso oficial del Gobierno sobre la pandemia ha sido contradictorio y confuso, y en el mejor de los casos ha tendido a enfocarse en la escasez de recursos y en la protección de libertades civiles, por ejemplo, las medidas de
* Doctor en Ciencias. Profesor y tutor del Programa de Maestría y Doctorado en Bioética, UNAM.

Correspondencia: RPM, ricardomsps@gmail.com Conflicto de intereses: Ninguno.

Citar como: Páez MR. COVID-19 en un país sin justicia social. Rev CONAMED. 2021; 26(2): 101-103. https://dx.doi. org/10.35366/100354 Financiamiento: Con recursos propios.

Recibido: 01/03/2021. Aceptado: 16/06/2021. 
distanciamiento. Del mismo modo, los mensajes contradictorios sobre el uso masivo del cubrebocas, - las medidas de contención que han sido muy relativas, y la eliminación de la jornada de sana distancia en el pico de la pandemia. Tampoco se han establecido programas integrales de apoyo a los que tienen que salir a la calle a trabajar para que puedan permanecer en casa, quedarse en casa para las mujeres representa en muchos casos un riesgo. Ante un sistema sanitario insuficiente y pauperizado, la tendencia obvia será olvidarse de quienes pueden ser presa fácil de contagios y cuya pérdida nos importe poco. ${ }^{6}$

Rescatando lo mejor de tales pronunciamientos, es decir, la insistencia en las medidas de aislamiento y contención, desde el punto de vista ético reflejan un imaginario establecido de desastre que orienta la respuesta por el camino del utilitarismo y de la autonomía. La historia de tales desastres y este tipo de respuesta tienen como consecuencia un agravamiento de la inequidad existente en la sociedad y en la salud. La respuesta utilitarista pide sacrificar a algunos para salvar más vidas, por ejemplo, los ancianos o quienes tienen baja esperanza de vida deben dejar los ventiladores a quienes los aprovecharán mejor. Se trata de problemas complejos que no tienen soluciones ideales y en los que habrá pérdidas, pero sin una revisión crítica, pueden sumarse al statu quo de confort donde el más privilegiado sobrevive a costa del más vulnerable.

Un asunto de fondo radica en la necesidad de un modelo ético explicativo alternativo que vaya más allá del individualismo biomédico, que entiende y maneja la pandemia desde el ámbito médico como si el COVID estuviera al margen de lo que sucede en la sociedad, la cultura o la economía, un modelo del bienestar que tome en cuenta la necesidad de cambiar los contextos y las redes de soporte de las poblaciones para atender y prevenir de fondo el COVID.?

La ética en torno a la pandemia debería orientarse por un modelo que dé cuenta de la naturaleza relacional de las personas como seres vulnerables insertos en redes existentes de cuidado. Un nuevo imaginario de desastre que ayude a comprender las interrelaciones de las privaciones sociales, políticas y económicas bajo las condiciones de distanciamiento social. Así por ejemplo, recomendar que es necesario llevar una vida sana, alimentarse de forma adecuada, dormir bien, no estresarse... sin atender los determinantes sociales de la salud es prácticamente inútil porque las personas no pueden salir de aquello que las obliga a permanecer en círculos viciosos que merman su salud.

Es necesario implementar un modelo de interconexión donde «todos nos salvamos juntos» o redes de soporte para detectar vulnerabilidades y fuentes de resiliencia, y ayudar a protegernos juntos desde una ética del cuidado. El confinamiento puede sacar lo mejor de nosotros mismos que significa desarrollar la capacidad de ver por los demás y es la clave de la solidaridad. Implica pensar la ayuda no como algo heroico, sino propio de nuestra naturaleza entendida como «cuidadores unos de otros». ${ }^{8}$

La vacuna contra la COVID promete ser una solución, pero desde la ética del cuidado y la solidaridad estará el reto de investigar y distribuirla con justicia y equidad, ${ }^{8}$ comenzando por los sectores más vulnerables y los trabajadores de la salud, evitando caer en la trampa de la comercialización de un producto más de la Industria Farmacéutica o de modelos utilitaristas o basados en el individualismo.

La salud es una valiosa meta para individuos y comunidades. Hay buenas razones para mejorarla: es un medio para que los individuos disfruten vidas florecientes y productivas; una población más sana es crucial para la economía de un país. Pero lo más importante es que la salud es un medio para otro fin más alto: el bienestar humano. ${ }^{9}$

\section{REFERENCIAS}

1. Pérez-Tamayo R. Patología de la pobreza. Nexos [serie en internet] 1983 [Consultado 2020, 09, 15]; [aprox. 3pp]. Disponible en: https://www.nexos.com.mx/?p=4215

2. Flamand L. Salud: la frágil protección social. Nexos [serie en internet] 2020 [Consultado 2020, 08, 28];[aprox. 7pp]. Disponible en: https://www.nexos.com.mx/?p=48605

3. Lemús J. El rostro de la pandemia en México: los pobres son los más afectados. Los Ángeles Times. 2020; 13.

4. Ruger JP. The injustice of COVID-19: we need a moral constitution for our planet's health. The Lancet Planetary Health [series on the internet] 2020 [Consulted 2020, 09, 05]; 4 (7): E264-E265. Available in: www.thelancet.com/ planetary-health

5. El Financiero Bloomberg TV [sitio de internet]. México: $2018^{\circ}$ Copyright, Grupo Multimedia Lauman, SAPI de CV 
[actualizado 2020, 09, 05; consultado:2020,08,15]. Disponible en: https://www.elfinanciero.com.mx/tv/cobertura-especialcoronavirus-en-mexico/71-de-mexicanos-fallecidos-porcovid-19-tenian-escolaridad-primaria-o-menor-estudio)

6. Vela BE. El virus y la discriminación. Nexos [serie en internet]. 2020 [consultado 2020, 08, 28]; [aprox. 2pp]. Disponible en: https://www.nexos.com.mx/?p=47869

7. Pascoe J, Stripling M. Surging solidarity: reorienting ethics for pandemics. KIEJ's special double issue on ethics, pandemics, and COVID-19 [series on the internet] 2020 [Consulted 2020, 10, 05]; [uncategorized aprox. 10 pp]. Available in: https://kiej.georgetown.edu/surging-solidarityspecial-issue/

8. Coleman CH. Equitably sharing the benefits and burdens of research: Covid-19 raises the stakes. Ethics Hum Res. 2020; 42 (5): 38-40.

9. Marmot M. Just societies, health equity and dignified lifes: the PAHO equity commission. Lancet 2018; 392. 